\title{
Advanced Biometric Voting Machine linked with Aadhaar and PAN Card
}

\author{
Mamta Varma ${ }^{1}$, Tasneem Vantmure ${ }^{2}$, Sanjna Sanjeev ${ }^{3}$, Nagshenkumar Waghmare ${ }^{4}$, Sejal Shah ${ }^{5}$ \\ K. J. Somaiya Institute of Engineering and Information Technology, Sion East, Mumbai, Maharashtra, India
}

\begin{abstract}
Article Info
Volume 7, Issue 4

Page Number: 77-81

Publication Issue :

July-August-2020
\end{abstract}

\section{Article History}

Accepted : 07 July 2020

Published : 22 July 2020

\section{ABSTRACT}

"Vote" means to choose a candidate from a list. By casting the votes, the Citizens choose a candidate from a list. Eliminating the bogus vote by linking the voting machine with Aadhaar card as well as Pan Card is the goal of the project. In this system, voting is based on Aadhaar and PAN databases. Since all the data is stored in the database of a particular place of a booth, such voting system is more efficient.

Keywords : Electronic Voting Machine (EVM), Aadhaar, PAN, Database, Fingerprints.

\section{INTRODUCTION}

Guidelines concerning the electronic approach and improvements towards prevention of false voting and a safe voting system is examined by this paper. To identify the voter and discuss other parameters that are implemented in this paper Aadhaar and PAN details are used.

Whenever the user goes to the balloting cubicle to give a vote he has to show his voter ID card. This is a tedious procedure as the certified individual has to verify the voter ID card with the register he has, validate it as an certified card and after that permit the individual to poll his vote but this method does not provide safety of the right candidate voting. Thus, to evade these kinds of troubles, fingerprint- based voting machine has been designed which uses Aadhaar and PAN card database to avoid bogus votes.

\section{LITERATURE SURVEY}

Sustaining the fundamental record of voters according to their reliability has been discussed by $\mathrm{K}$. Mallikarjuna et al. Having each and every polling station can help in maintaining its narrow record and can also update the fundamental record following the conclusion of the online voting procedure. Radio Frequency Identification, Biometric Security, and Secret Pin Authentication Phase are also some aims provided in their paper. When voter casts a vote, the condition of that elector is patent correct so that the same elector can't cast vote more than once. Each voter is provided with an RFID card ${ }^{[1]}$.

A safe online e-voting method which utilizes Unique Identification Authority of India or Aadhaar features as its rear-end was projected by Rohan Patel et al. Matching fingerprints and qualification is analyzed

Copyright: (C) the author(s), publisher and licensee Technoscience Academy. This is an open-access article distributed under the terms of the Creative Commons Attribution Non-Commercial License, which permits unrestricted noncommercial use, distribution, and reproduction in any medium, provided the original work is properly cited 
by testing the age of the elector so fashioning the available pick cards unnecessary in the structure guarantee validation. They need to scheme associate integration of the Classless Inter- Domain Routing, thereafter, of electronic voting scheme to generate electronic voting in India practically.

During this project, Client-Server web facilitated software plan is in work. A client interface permits Aadhaar number of voters then offers a correlated crossing point to cast a vote and shows affirmation, status and fault points. Intelligent info assesses and high-speed net connection within the process is needed in such technique ${ }^{[2]}$.

Using the fingerprint records of the Aadhaar Card in the ballot vote method has been discussed by B. Mary Havilah Haque et al. One of the advantages of this project is that if a person who consumed alcohol enters the ballot stand, a signal will make the authorized individual who is in charge of the voting responsibility aware. The enroll button is provided in this project for enrolling purposes. Vote will not cast if a citizen is not enrolled in his vote on the information of the microcontroller ${ }^{[3]}$.

The requirement of voter identification as discussed by Prof.

R. L. Gaike et al, the election process has two phases: first is when voter registration is established with the right to cast a vote and then to sanction an elector to use their right to cast a vote by confirming if the individual assures each and every requirement needed to cast a vote is performed during balloting time. An important key to any voting system is security. The specifics of the elector will be taken from the Aadhaar card record in this method. The voter's detail is held on within the PC by using the information they took. They use a finger-sensing module for fingerprint access throughout the election ${ }^{[4]}$.

An online voting system for Indian Elections has been described by R. Murali Prasad et al. In this, Aadhaar card number and password is used by all users to $\log$ in. Prior to the election received in the major record of ECI, the high- security password has to confirm. The record of Aadhaar card is accumulated in the computer. After equating the fingerprint, the elector is obligated to push the switch committed to its following candidate. Finally, a token will be printed that contains the details about the vote the user casted $[5]$.

\section{METHODS AND MATERIAL}

\section{A. Existing System}

M3 versions with VVPAT capability are the existing electronic ballot vote machines in India. M1 and M2 being the older versions. At the state-owned and high-security premises of the Bharat Electronics Limited and the Electronics Corporation of India Limited, these machines are built and encoded with read-only software. On a real-time basis with EVM Tracking Software (ETS), that is securely tracked by the Election Commission of India. Its digital verification identity and physical presence is tracked by this system. Embedded hardware and software are present in the M3 EVMs. Issued by the Election Commission, as another layer of tamper-proofing, they enable only a particular control unit to work with a particular voting unit. Additional means of tamper-proofing the machines include several layers of seals. Indian EVMs are stand-alone non-networked machines.

\section{B. Problems with Existing System}

- The EVMs are susceptible to manipulations by fraudulent, since they move through different hands, therefore.

- Inefficient process of identity checking: Since less or more identical look alike personals can provide the ballot on behalf of another. Legal electorates are verified by ballot representative by their photos on the voter card.

- Susceptible to manipulations: An assailant can straightforwardly examine and note down the 
EEPROM chips that accounts the vote by attaching additional hardware to the circuit of the control unit.

- Natural Hazards: Damage to the EVM chips and internal circuitry can be done by high temperature, humidity, and harsh climatic conditions. Moreover, attack by vermin, rats, fungus or mechanical danger can generate malfunctions.

\section{Proposed System}

\section{Working Procedure of the proposed system}

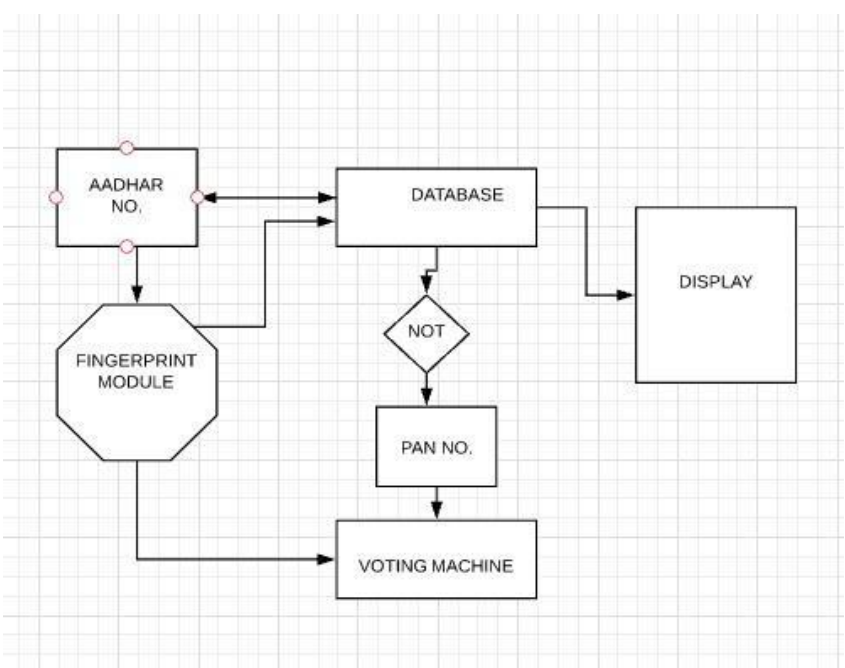

Figure 1. Block diagram of the proposed system

\section{FLOWCHART}

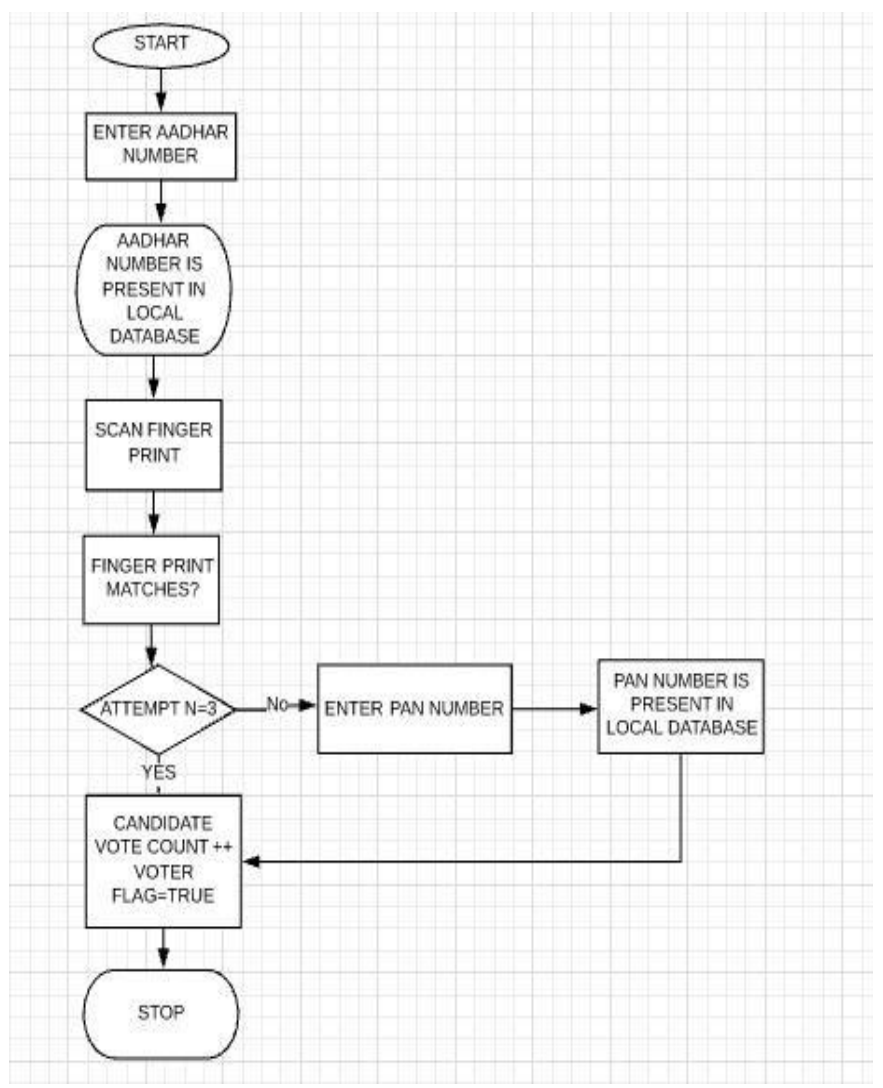

Figure 2. Flow chart of the proposed system

The system that has a database that stores Aadhaar and PAN information. Fingerprint module is used for Aadhaar verification. Database is used activation of voting machine.

\section{Operation}

1. Start

2. Enter Aadhaar number if present in the local database then only allows for the fingerprint.

3. If the fingerprint does match with our local database, then EVM will be turn on automatically (Here fingerprint is sonly used to activate the EVM it does not store personal details.).

4. If the fingerprint does not match, then we will allow to voter for physical verification of PAN and then allow entering PAN details. 
5. After EVM gets on a voter can cast a vote.

6. They are using an LCD to display the remaining candidate who has not cast vote.

7. End.

\section{RESULT}

The System is highly reliable and secure. When compared to present systems the maintenance cost is very less. Checking for illegal practices like rigging in elections can be done. Getting instantaneous results \& with high accuracy is possible.

\section{CONCLUSION \& FUTURE SCOPE}

This project enhances the security by eliminating the bogus votes and vote repetition, as it uses Aadhaar Fingerprint as well as PAN details for alternate option. Still in this project instead of using fingerprint and PAN detail one can upgrade it by using another unique human identification (such as using human iris and face detection in Aadhaar instead of fingerprint).

\section{VII.REFERENCES}

[1]. K. Mallikarjuna and T. Mallikarjuna: - Biometric fingerprint based electronic voting system for rigging free governance, May- 2014.

[2]. Rohan Patel, Vaibhav Ghorpade, Vinay Jain and Mansi Kambli: - Fingerprint Based e-Voting System using Aadhaar Database, March-2015.

[3]. B. Mary Havilah Haque, G. M. Owais Ahmed, D. Sukruthi, K. Venu, Gopal Achary and C. Mahendra Naidu: - Fingerprint and RFID Based Electronic Voting System Linked With AADHAAR for Rigging Free Elections, March2016
[4]. Prof. R.L. Gaike, Vishnu P. Lokhande, Shubham T. Jadhav and Prasad N. Paulbudhe: - Aadhaar Based Electronic Voting System

[5]. Prasad, R.M., Bojja, P. And Nakirekanti, M.: Aadhaar Based Electronic Voting Machine Using Arduino, 2016

[6]. Mishra R, Bagde S, Sukhdeve T, Shelke.J:-Review on Aadhaar Based Voting System using Biometric Scanner4.

[7]. International Conference on New Scientific Creations In Engineering And Technology

\section{AUTHORS PROFILE}

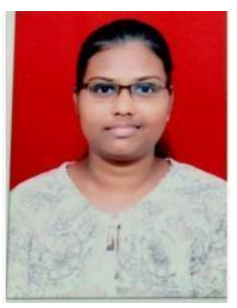

Mamta Varma received her Bachelor's Engineering in Electronics Engineering from the University of Mumbai in 2020. She also has completed her diploma in Electronics Engineering in 2017

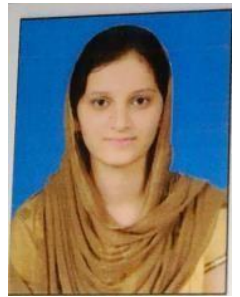

Engineering in Electronics Engineering from the University of Mumbai in 2020. She also has completed her diploma in Electronics \& telecommunication in 2015

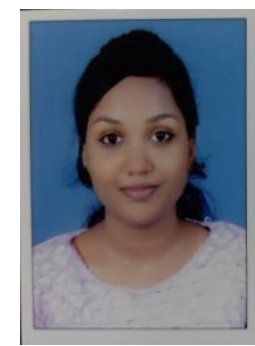

Sanjna Sanjeev received her Bachelor's Engineering in Electronics Engineering from the University of Mumbai in 2020. She also has completed her HSC in Science stream in 2015

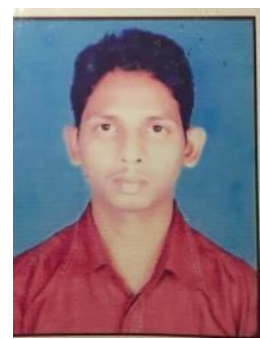

Nagshenkumar Waghmare received his Bachelor's Engineering in Electronics Engineering from the University of Mumbai. He also has completed her diploma in Industrial Electronic in 2017

Tasneem Vantmure received her Bachelor's 


\section{Cite this article as :}

Mamta Varma, Tasneem Vantmure, Sanjna Sanjeev, Nagshenkumar Waghmare, Sejal Shah, "Advanced Biometric Voting machine linked with Aadhaar and PAN card", International Journal of Scientific Research in Science and Technology (IJSRST), Online ISSN : 2395-602X, Print ISSN : 2395-6011, Volume 7 Issue 4, pp. 77-81, July-August 2020. Available at

doi : https://doi.org/10.32628/IJSRST207310

Journal URL : http://ijsrst.com/IJSRST207310 